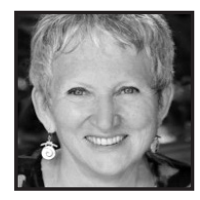

\title{
Thinking Ecologically About Educational Contexts and Community
}

\author{
Anne McCrary Sullivan
}

\begin{abstract}
Taking the Earth Charter's preamble as a beginning, this work calls for "ecological thinking" as a way of seeing and interpreting an interdependent world where we seek "to bring forth a sustainable global society founded on respect for nature, universal human rights, economic justice, and a culture of peace." Incorporating poems and personal reflections, this braided essay grows out of the author's experiences in Everglades National Park. As defined by Corey (2016), the braided essay offers "various threads of writing...nearly always without overt transition...," each part having its own meaning, within "an obliquely accumulating larger impact" (pp. 7-8).
\end{abstract}

We stand at a critical moment in Earth's history, a time when humanity must choose its future. As the world becomes increasingly interdependent and fragile, the future at once holds great peril and great promise. To move forward we must recognize that in the midst of a magnificent diversity of cultures and life forms we are one human family and one Earth community with a common destiny. We must join together to bring forth a sustainable global society founded on respect for nature, universal human rights, economic justice, and a culture of peace. Towards this end, it is imperative that we, the peoples of Earth, declare our responsibility to one another, to the greater community of life, and to future generations.

-Preamble to The Earth Charter (http://earthcharter.org/discover/the-earth-charter/) 


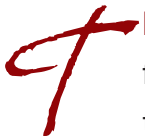

hese are monumental goals. We may embrace these ideals and still feel at a loss to know how to bring them into reality. We may "recognize that in the midst of a magnificent diversity of cultures and life forms we are one human family and one Earth community...." But how exactly do we "join together to bring forth a sustainable global society," one that is "founded on respect for nature, universal human rights, economic justice, and a culture of peace?" What can an individual or a small group of geographically isolated people do? What can educators and teacher educators do within prescribed curricular demands?

It's a question I think we must ask ourselves over and over, wherever we are. Each of us will make our way to different answers. All our answers will be partial. But our collective partial efforts have the possibility of constructing something larger than ourselves, something on a scale that represents "human family" and "Earth community." The stakes are high. We must try.

\section{Everglades Wilderness Writing Expedition}

November 2, 2014: I have watched the stars fade and a faint blue come to the sky. Silhouettes of mangroves that embrace this small cove now take on detail and subtle color. A line of pelicans flies low over the treetops. Our plywood raft, constructed last night over the aluminum canoes in which we paddled here, sways slowly back and forth on the water. My companions are still sleeping or just beginning to rouse under their net drapings. They are young and strong, but tired after yesterday's strenuous effort and cognitive demands. They have never done anything like this before.

In a couple of hours, after breakfast and coffee and putting away sleeping bags and nets, we will gather at one end of this floating platform with our journals and pens, and I will teach a writing lesson. Here, in the mangrove wilderness, my teaching life and my naturalist life have fully merged.

\section{Writing and Teaching in a National Park}

"...explore how collaboration between educational contexts and communities can enhance mutual and relevant learning" (Call for manuscripts, LEARNing Landscapes, Linking Education and Community: Present and Future Possibilities)

The call for manuscripts for this edition of LEARNing Landscapes does not pre-define either "educational context" or "community." We are invited to think broadly about 
meanings and possibilities. I am thinking, for now, about my engagement with Everglades National Park, how that engagement has entered my teaching and my thinking about both educational contexts and communities.

I first arrived in Everglades National Park as a poet-in-residence. I was on sabbatical, leaving my educator role behind for a while. A guest of the National Park Service, I was invited to spend an entire month living inside the Park and responding to that remarkable environment in poems or whatever other writing I might be drawn to do. I had been teaching for over 20 years, first in high school and then at the university level. Schools were my "educational contexts." A national park was part of "the community." But within a relatively short period of immersion in the Park, I came to identify the Park as an "educational context" and anything outside the Park, including schools, became "the community." It was a surprising reversal of perspective. And I soon learned that I could not detach from my teaching self so easily.

As I followed rangers on guided walks, taking notes and sometimes using a digital recorder to gather their words, I found myself paying attention to myself as learner and to rangers as teachers. Within 36 hours, I had become a voracious learner. At first, the knowledge I wanted was simple: I wanted to know the names of things.

\section{(1)) What Is This Frenzy of Naming?}

Every day I go out with guides and charts, checking undersides of leaves, subtleties of feather, splotches on bark. I want to know the names, be able to say good morning buttonbush, good morning glossy ibis, good morning gumbo limbo as though by naming I might claim an intimacy. Intimacy requires more. Intimacy is slow. It knows not only what's here but what has been and what is forming in the bud. For that I must stay, know the subtle 
rhythms of a year-what comes and goes

and comes again, sound of it, color of it, shape and smell, sting and flower, how the tangle

thickens then recedes, where waters move, what burns. Now, the early sun

spreads over sawgrass. Dew dries. Water brightens.

One great blue heron arrives at the usual place.

All day he will stand there.

(Sullivan, 2009, p. 46)

Day after day-less perfectly still than the heron but also hungry-I stood on the Anhinga Trail studying with my eye, my ear, the field guides in my backpack. First I learned the names and then more deeply the ecological relationships. I went from what is this? to why is this here? and why does it matter?

By the end of my month in residence I had learned enough that I was permitted to don a volunteer uniform and serve as guide on the regularly scheduled ranger-led walk of the Anhinga Trail, most visited trail in the Park. Through my interpretation, I wove fragments of poems (my own and poems of others) that I judged to have value for the moment and what we were seeing. I had, in spite of myself, reclaimed my role as teacher.

Following the residency, I continued my learning and expanded my naturalist training. I returned to the Park as a volunteer and led many walks on the Anhinga Trail. Ultimately, however, I knew that my primary work for the Park would not be as naturalist-guide, but would grow more directly out of what I brought to the Park in the first place, my background as a writer and teacher.

\section{Interpretation as Teaching: Freeman Tilden, John Dewey, and Me}

Within the U. S. National Park Service, each Park has its Division of Interpretation apart from the Division of Environmental Education. The latter works closely with schools and school systems and focuses directly on education of the young. The Division of Interpretation is engaged in educating any and all who come to the Park (and some who don't), leading walks, giving talks, designing visitor center and wayside exhibits, developing printed materials, and engaging in outreach to "the community." 
Freeman Tilden is a name that I came to know early in my experience as a volunteer interpreter. In his 1957 classic, Interpreting Our Heritage, Tilden outlines six "Principles of Interpretation" which have become foundational in the field of interpretation. From my first contact with Tilden's principles, I felt in familiar territory. Consider, for example, Principle \#1: "Any interpretation that does not somehow relate what is being displayed or described to something within the personality or experience of the visitor will be sterile" (Tilden 1957/1977, p. 9).

I cannot read this without thinking of John Dewey: "the lack of any organic connection with what the child has already seen and felt and loved makes the material purely formal and symbolic....it remains an idle curiosity...." (Dewey 1902/ 1990, p. 202). Recent brain research suggests that this is true for adults as well as for children (Sousa, 2006, p. 141). We have learned that isolated, detached facts, however curious, are hard to remember and have little meaning within the context of an individual consciousness. Personal and intellectual connections are important for meaning-making, valuing, and memory.

I am also on familiar pedagogical ground as Tilden (1957/1977) asserts that "the chief aim of interpretation is not instruction, but provocation" (p. 9). I read "provocation" and remember Dewey's (1902/1990) assertion that if connections are not established "between the mind and its material," the "thought-provoking character" (pp. 202-204) of the material is lost or obscured.

So as I walk along the Anhinga Trail in my role as guide, I think about how to create for the visitor a sense of connection-either emotional, aesthetic, practical, or historical. It's not enough to walk beside the water and call attention to how clear it is. I must talk about where that water comes from and where it goes, how that same water makes its way into hotel faucets in Miami where they will brush their teeth, how it travels to the Gulf of Mexico to mix with salt water and create an estuary which serves as a nursery for the seafood they love to eat. It's not enough to point to the alligator sunning on the bank. I must acknowledge the nervousness a visitor may feel in this creature's proximity, explain how in their natural environment, alligators do not see us as prey; how I, too, am fearful of them in urban environments where their natural instincts have been confused but not here, where they live their normal alligator lives.

These are small connections. Because I do not know these visitors personally, because our time together is brief, small connections are the best I can do. And at some point in my interpretation, when some of the small connections have 
generated attention and interest, I can offer something "thought-provoking" in Dewey's words, a "provocation" in Tilden's. I can lift from shallow water a dripping mass of "yucky" stuff, call it periphyton, and propose that everything in the Everglades depends upon that soggy mass which harbors microscopic organisms at the bottom of the food chain. I can talk about how alligators have shaped the landscape, how "everywhere you see a hill, it's likely a hole." I can propose that nothing is expendable. Everything is connected to and dependent upon everything else. We need the periphyton. We need the alligator. We need the water and its flow.

And then they go away. And the truth is, I have no way of knowing whether they really were "provoked" to additional thought or additional attention, or whether they might seek additional experience in other national parks where they might learn about different plants, animals, landscapes, but discover that the ecological principles of interdependency are the same.

\section{Becoming a Naturalist}

Soon after my month as poet-in-residence, I returned for another month as a volunteer naturalist. My reflections deepened. I thought a great deal about how my work in the park connected with my teaching life as I had known it. As I led walks and gave talks, as I told stories about particular plants and animals, their eating habits, their mating rituals, as I sought ways to help visitors make their own connections with this wild and beautiful place, my participants often assumed that I had been living in the area "a long time." I began to wonder: how exactly had I learned so much so quickly?

I thought of a text that I used in teaching, Caine and Caine's (1994) Making Connections: Teaching and The Human Brain, what that text says about the power of orchestrated immersion for learning: "When wholeness and interconnectedness cannot be avoided, students are obliged to employ their locale memory system in the exploration of content" (p. 115). My locale memory system had been in high gear. I was completely surrounded by and immersed in what I was studying. Everywhere I turned, there it was, and because I was paying attention to it in a heightened kind of way, establishing a sense of connection, I was absorbing information like the proverbial sponge.

Caine and Caine also speak of metaphor-making in relation to learning: "Metaphors are intrinsic to the construction of new knowledge and at the heart of the acquisition of felt meaning" (p. 123). As I had gone about the work of poetry, metaphor-making had played a significant role in my learning. It wasn't that I 
had set out to deliberately construct metaphors for poetry. Metaphors emerged, rather, from detailed observations and descriptions. Although I must have been constructing metaphor on some subconscious level, on the conscious level I was discovering metaphor, connections already there. Lakoff and Turner (1989) write of metaphor as conceptual mapping, a way of negotiating meaning. This is not a matter of the schoolroom definition of metaphor as a linguistic device for comparison without using "like" or "as." This is about a whole network of understandings, a set of relations between the seen and the unseeable. As I explored the tangible landscape and its complex ecological relations, my subconscious was mapping its relations with my own unseeable interior. It was this network of relations between the world and the self, this ecological way of seeing and thinking, that made learning profound and lodged it in memory.

\section{Bringing a New Passion Into Teacher Education}

Following the freedoms of my sabbatical year, I returned to teaching not exactly the same person as when I left. I was invigorated by new local knowledge, a sort of knowledge that I had never incorporated into my teaching, but that now seemed both personal and important beyond my own experience. I had a deeper awareness of the local as part of the global. What was I going to do with this new passion and all this new knowledge? Was this relevant for my students and for their work?

I was teaching then in a graduate program in Interdisciplinary Studies in Curriculum and Instruction. I worked with cohort groups of K-12 teachers throughout their program, teaching multiple courses and guiding their action research. In any cohort, the teachers were from a variety of disciplines.

We all lived in Florida - a beautiful, amazing state whose richness and complexity I had only really begun discovering during my sabbatical, although I had lived in the state over a decade. I knew that many of my students were as oblivious as I had been to the immediate natural world in which we lived. Many of them taught units on the Amazon Rain Forest (which is a wonderful thing to do), but they never mentioned the Everglades or examined the delicate and complex ecosystems in which they and their students actually lived.

I have often told my students: invent ways to bring the positive energy of your passions into your teaching. Now, I was feeling challenged to figure out how to do that myself. 


\section{A Small Beginning in Myakka River State Park}

I began planning for a learning Saturday in Myakka River State Park, a daylong orchestrated immersion. This park is in the county where most of these teachers lived and worked, but only two of the 18 had ever been there. I wanted to introduce them to a rich ecological and recreational resource on their doorstep, for their own sakes and also so they could tell their students about it. Most were teaching in inner-city schools. Their students did not take vacations to Costa Rica or even to the Everglades on the other side of the state. Perhaps these teachers would tell their students about an adventure in a park not far from where they lived. Perhaps they would want to go there someday. I also hoped to catalyze thinking about how to integrate local knowledge with existing curriculum, connecting here with there, now with then. With these goals in mind, I wanted to offer an experience locating the extraordinary in the ordinary, invite them into thinking about how children who don't take vacations might find wonder and surprise in the everyday world.

For example, there is a plant that grows on almost every roadside in Florida (and in many other states, too) called wax myrtle. It is the most ordinary of ordinaries, but it has a leaf shape and a growth habit that make it easily identifiable, and it has a story. This plant was very important for early settlers in Florida. Its berries were used to render a light green scented wax that was used for candle making. Pioneers often planted wax myrtle by the doorstep because it discouraged fleas; they crushed the leaves and put them under the bed or in corners of the house to repel roaches; and they found a number of medicinal uses for the plant. Botanist Daniel Austin (2004) recollects watching flocks of thousands of tree swallows as they would "spiral down to the wax myrtle bushes and snatch off berries." Austin writes that when he first observed this phenomenon, he "thought it was a tornado" (p. 450). What a wonderful plant this wax myrtle is, growing wild by the roadsides!

We met at the park gate at 8:00 a.m., opening time, and then went directly to the canopy walk. There, one by one, each ascended a wooden tower alone, keeping silence. I used a stopwatch to space walkers by a minute and a half, creating a small solitude for each walk through the treetops, across a narrow, hanging walkway, to a second tower which offered a panoramic view of wetlands and palm hammocks, hawks and vultures soaring. I asked them to take their journals with them and to make a journal entry from the second tower, sustaining silence until they had come back down. Later, many of them would name the canopy walk as one of their favorite experiences of the day. 
I discovered that I need to find more alone time for me in places like the canopy walk to reflect and feel serene. I walked up there and my stress just melted away. I didn't want to come down.

I enjoyed the experience of the canopy walk, the quiet moments spent thinking and watching the natural world around us. It made me appreciate its beauty, and I discovered that I liked the openness. I've always been frightened of being isolated from the business of the city and people. But it was so peaceful up there.

A primary theme for the rest of the day at Myakka was "What's so special about....?" Teams were assigned the task of finding out what's so special about an oak tree? or a cabbage palm? or airplants? Each team had a different set of assignments, and each was required to use five sources of information as they tried to ferret out the extraordinary qualities of ordinary things. They could learn from park interpretive signs, from displays or films in the visitor center; from their own direct observations; they could ask a knowledgeable human being; or they could consult resources in the portable library I had brought in the trunk of my car. Then, in the afternoon, after our picnic lunch under the cabbage palms, they taught each other about the extraordinary qualities of the ordinary mass of green by which we were surrounded.

In soliciting their feedback a week after the experience, I deliberately asked very broad questions: What surprised you? What did you take away from the experience? They wrote spontaneously for five minutes in class. Many of them spoke of the "serenity" of the park experience, a sense of "renewal" and "peace." I began to realize that part of the value of an experience like this relates precisely to the fact that these teachers rarely have a moment to themselves, a moment out of the rush and press of demand. They had learned that without actually going far, they could feel far removed from their everyday stresses.

It was interesting how many of them mentioned overcoming some sort of fear. Of the canopy walk, remember: "I've always been frightened of being isolated from the ... city." One wrote, "Once I overcame my fear of falling, the canopy walk was breathtaking" Another wrote,

I knew there was a chance that I might 'accidentally' see a snake. I was worried about that from the time that I knew we were going till the time we pulled in the parking lot. But once we began researching, I slowly began to forget my fear. 
They also wrote of their new knowledge and suggested personal meanings for what they had learned:

I never really considered which plants and trees were native to Florida or questioned their significance. I found myself paying attention to trees this weekend and respecting their jobs as being habitats for various animals and providers of clean air for me. I fell in love with the magnolia tree and have decided that I would like one for my yard. I even paid more attention to my beloved gardenia. I made a trip to the store after researching its needs online. I've become aware that there's more than meets the eye in nature and that taking a simple walk with my students or my daughter can be a learning experience as long as I am open minded.

I discovered that there is so much more to "wildlife" than I realized. When I was driving home, every tree I looked at I tried to compare to one of the kinds of oak trees I had found out about. I was surprised that I retained more information than I thought I would.

There is so much natural Florida. It felt like another world. But it shouldn't. I'd like to teach my kids more about Florida's history and environment.

Terry Tempest Williams (2003) reminds us that "the Earth Charter is an ideal. It is a visionary document that creates a template for ecological consciousness around the world, rooted in local actions. It asks us to embrace the planet while taking care of our own backyards" (p. xiii).

During our day at Myakka, these teachers clearly made unanticipated personal connections with the natural world in their own backyard and in doing so, took a first step in learning to think ecologically, whether or not the topic is the natural world.

John Muir (1911/2004) has written, "When we try to pick out anything by itself we find it hitched to everything else in the universe" (p. 87). Jared Diamond (2011) repeatedly points out connections between environmental degradation, poverty, and social collapse. And most of us have come to understand that simple solutions to complex problems will inevitably fail because they do not acknowledge the ways in which things are "hitched together." Long is the trail of abandoned "solutions" to educational challenges; many are the accumulated unintended consequences. I would suggest that these failures are often the result of not thinking clearly about the complex relationships among elements of a problem or context. They are failures to think ecologically. 


\section{Everglades Wilderness Writing Expedition: Mascara}

In the spring of 2014, Ranger Sabrina Diaz of Everglades National Park sent out a call for applications. Any student in a journalism or creative writing program in one of the colleges or universities of south Florida who was willing to take on a challenge, was invited to fill out the application form and submit writing samples. Preferred applicants would have little or no experience of Everglades National Park and little or no experience of wilderness.

Ten students were selected to participate in a series of experiences which would culminate in a four-day canoe expedition into mangrove wilderness. The logistics of the expedition would be managed and our guides provided by Outward Bound (http://www.outwardbound.org/about-outward-bound/outward-bound-today/). I was invited to join the expedition as their writing teacher.

On the launch date, we gathered at the water's edge. We had been sent a list of items to bring and been told to bring only those items. Guides Russ and Aaron instructed all participants to empty onto tarps the contents of our packed drybags. As they called the name of each item, we were to put that item back into our bag. Anything they had not called for us to repack would have to be left behind. I very quickly spotted Zoraida trying to sneak in her mascara.

\section{Thinking Ecologically}

"We must join together to bring forth a sustainable global society founded on respect for nature, universal human rights, economic justice, and a culture of peace." -Preamble to The Earth Charter

What do alligators, wax myrtle, and a mangrove wilderness have to do with "universal human rights, economic justice, and a culture of peace?" Why are lofty human concepts included in the same document, much less the same sentence with "respect for nature?" In order to understand, we have to think ecologically. We have to become conscious of the interconnections and deep relationships between, for example, environmental degradation and poverty.

As Quammen (2008) reminds us, "The absolute poor will suffer their lack of ecological privilege in the form of lowered life expectancy, bad health, absence of education, corrosive want, and anger" (p. 187). Consider fishing villages in coastal areas all over the globe where environmental degradation or climate change or overfishing 
have resulted in fishermen having to travel farther and farther for fish they used to catch close to home; their increased travel meaning increased expense and their marginal catch meaning decreased income (Cunningham, 2015). Consider how poverty leads people in Africa or the Amazon to cut down forests for cooking fuel and trap endangered species for meat or to sell, practices which further diminish their scanty available resources and increase the desperate spiral of poverty. Consider how women and girls, in parts of the world where clean water supplies are not secured, must spend so much time walking to water and carrying it back to their villages, that there is no time for education. Consider that wealthy corporate interests may exploit natural resources for their own additional enrichment, depriving critical access to native peoples who become dependent and poor. Consider that wars arise over natural resources, including oil, and that some predict major wars of the not-too-distant future will be fought over water rights. The relations of ecology and economy, environment and education, resources and culture are complex and deep.

\section{Everglades Wilderness Writing Expedition}

As we gathered at the shore, preparing to paddle, Zoraida Pastor "didn't fully grasp the reality of what it meant to camp in the backcountry." She began to have clarity when "our trip leaders ... asked me to leave behind at least half of what I was planning to bring. Out went six outfits and my concealer and mascara. How can a city girl survive without those essentials?"

Later, in a short article titled "Does This Outfit Match My Canoe?" (Pastor, 2015), Zoraida begins, "I am a city girl and one of the most feminine women you will ever meet. I was born in heels." She describes her high school self as "Madame Popular, highly perfumed and accessorized" and acknowledges that "it might seem surprising" that she would apply for a wilderness program. A friend who was applying convinced her to do it.

\section{Educational Contexts and Community}

Our separations of "educational context" from "community" have often, I suspect, been arbitrary or hierarchical. How might we have been limited by this? How well do we think about the complex whole? How well do we find inherent connections and build upon those, bring them into flourishing? How do teachers in one context become learners in another? And vice versa? The world is a complex of educational contexts, interconnected and interdependent. How well do we understand that? 
The Everglades made me a learner in a new domain and reinvented me as a teacher. The natural world and its ecological relations have taught me deeper dimensions of thought about the local and the global, the natural and the social. As I look at the goals of the Earth Charter, I know the smallness of my role in this very large endeavor. But because I am thinking ecologically, I know that every small part of a system matters to every other part. I teach, I guide, I write in the belief that even though I can't always see how, it makes a difference as part of the web of connections that is essential for enacting "our responsibility to one another, to the greater community of life, and to future generations" as the Earth Charter calls us to do.

We will get to a "sustainable global society" one action at a time, every action partial but a vital part of the whole. Laws, manifestos, the Earth Charter may serve as guides, supports, or inspirations, but without the actions of individual people, they are nothing. "'Change,' the social-justice activist Tom Hayden wrote, 'begins in the individual lives of countless people when they no longer accept existing conditions as inevitable'" (Cunningham, 2015, p. 43).

We do not have to drop what we're doing and dash out to save either the natural or the social world. Nor do we have to feel the challenge is too great and turn away. Rather, thinking ecologically, we can understand that those who are working for environmental health, whether or not they realize it, are working for social justice and global peace. Those who are working for social justice, whether they realize it or not, are working for a sustainable environment. Those who are working for peace are working for a world in which depleted resources will not become the motivation for war. All of our efforts may be enhanced if we can think ecologically about these relations, be supportive of each other's efforts, and think creatively about how we might work together. Simply by making cross-disciplinary and cross-cultural connections, teachers at all levels, whatever their subject matter, are in a position to model and teach ecological thinking.

Such thinking also opens the way for teachers to bring their own out-ofschool passions into meaningful conjunction with curriculum. "Follow your bliss," urges Joseph Campbell (1991, p. 118) and doors will open where there were only walls before. In curriculum, too, this is true. Thinking ecologically, we can discover connections that have been there all along but mute, unacknowledged-art in the science classroom, fishing in social studies, baking in math. We can make connections between what we love and what we teach. We can make connections between what our students love and what we teach. Everything is connected to everything else. This is what ecology teaches us. And we can believe with Liz Cunningham (2015) 
that "We, our words, our actions, all the gestures, small and large, they stream out into the future in ways we'll never fully fathom" (p. xxi).

\section{Everglades Wilderness Writing Expedition: A Powerful Hybrid}

Dylann Turffs was engaged with the natural world before she joined the expedition, and she brought no mascara. She writes of making connections.

For me, the most important aspect of the experience was the connection between nature and creativity. Until then, my interest in both had been compartmentalized. Among my writer friends, I was the only one who wrote about nature. Among my hiking or diving friends, I was the only one who read poetry. I had not yet found a way to connect them. The experience was validating in that it acknowledged the intrinsic connection I have always felt between nature and art, and it gave me a way to explore it. (personal correspondence)

And Zoraida: in those four days in wilderness, she paddled hard against wind and tide, worked with her teammates to sustain direction, cooperated in the setting up of our floating camp. She learned to live without mascara and transformed her vision of herself and the world. She's back in high heels, perfectly made up, her hair and her clothes glorious, but she is not the same. She now identifies as "a powerful hybridcity girl, wilderness woman." She writes,

Those four days in the Ten Thousand Islands area of Everglades National Park were a guidebook to the rest of my life.... I am now ever in need of natural places, wide open spaces, where I have learned to find myself, or a piece of myself.... As a writer and journalist, I want to explore more of these wild places-and I want them preserved for future generations.

\section{Mosquitoes, Poems, and the Community of Life}

"Compassion is the keen awareness of the interdependence of all things."

-Thomas Merton (cited in Nichols, 2014, p. 244)

Direct encounters with the natural world have been important for me in my evolution as an educator. Since that sabbatical year in the Everglades over a decade ago, the lines between "educational context," "community," and "natural world" have blurred. I have a greater sense of the natural world as educational context and a 
greater sense of how connected local communities are to the global community of life-human and nonhuman.

The Everglades have made concrete for me something I have known but that has sometimes seemed abstract-that every small part of the whole matters. Even the mosquito has a role to play:

\section{v)) Blood Meal}

I eat of lemon bacopa.

The mosquito drinks my blood.

My eating is ritual.

Her eating is life.

No difference.

We do what we must.

She pollinates the orchid,

lays her eggs.

I look for myself

blooming in the branches.

(Sullivan, 2009, p. 79)

Perhaps there is a role for small poems, too. John Felsteiner (2009) raises the question in his book Can Poetry Save the Earth? His exploration of the question does not lead to a definitive answer, but he writes, "Science, policy, and activism point the way towards solutions, but something deeper must draw us there" (pp. 13-14). We must care. We must feel connected. "[R]eacting to a poem's pulse and images may strike deeper than policy pronouncements" (p. 356).

And so, I continue to go into the natural world to teach and to write in ways that I hope will offer people a sense of connection, ways that may generate empathy and compassion. I go to be sensitized and to remember in a visceral way that "we must join together to bring forth a sustainable global society." I go to secure my faith that our collective efforts do matter "to the greater community of life and to future generations." 


\section{References}

Austin, D. (2004). Florida ethnobotany. Boca Raton, FL: CRC Press.

Caine, R. N., \& Caine, G. (1994). Making connections: Teaching and the human brain. New York: Addison-Wesley.

Campbell, J. (1991). The power of myth. New York City: Anchor Books.

Corey, S. (2016). To our readers. The Georgia Review, (Spring) 70(1), 7-8.

Cunningham, L. (2015). Ocean country. Berkley, CA: North Atlantic Books.

Dewey, J. (1902/1990). The child and the curricuIum. Chicago: University of Chicago Press.

Diamond, J. (2011). Collapse: How societies choose to fail or succeed. New York City: Penguin Books.

Felsteiner, J. (2009). Can poetry save the earth?: A field guide to nature poems. New Haven, CT: Yale University Press.

Lakoff, G., \& Turner, M. (1989). More than cool reason: A field guide to poetic metaphor. Chicago: University of Chicago Press.

Muir, J. (1911/2004). My first summer in the Sierra. Mineola, NY: Dover Publications.
Nichols, W.J. (2014). Blue mind. New York: Back Bay Books.

Pastor, Z. (2015, May 1). Does this outfit match my canoe? National Parks Conservation Association. Retrieved from https://www. npca.org/articles/445-does-this-outfitmatch-my-canoe.

Quammen, D. (2008). Natural acts: A sidelong view of science and nature (2nd ed.). New York: W.W. Norton \& Company.

Sousa, D. A. (2006). How the brain learns. Thousand Oaks, CA: Corwin Press.

Sullivan, A.M. (2009). Ecology II: Throat song from the Everglades. Cincinnati, $\mathrm{OH}$ : WordTech Editions.

Tilden, F. (1957/1977). Interpreting our heritage. Chapel Hill, NC: University of North Carolina Press.

Williams, T. T. (2003). Taking the globe to our Boston. In A voice for Earth: American writers respond to the Earth Charter. P. B. Corcoran \& A. J. Wohlpart (Eds.). Athens, GA: University of Georgia Press.

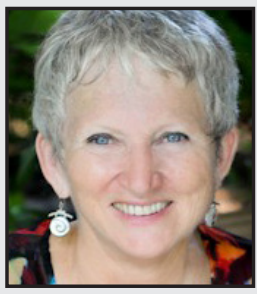

Anne McCrary Sullivan is a poet, naturalist, and independent scholar. She has had a long career teaching at high school and university levels and now teaches primarily in informal contexts. She is a Florida Master Naturalist, a Fulbright Scholar, and Professor Emeritus of Interdisciplinary Studies in Education at National Louis University. 